\title{
Discussion on the University Laboratory Service Mode Facing "Middle School Scientific Quality Education"
}

\author{
Ling Hong \\ School of Transportation Engineering \\ Tongji University \\ Shanghai, China \\ ss980308@tongji.edu.cn
}

\author{
Shunhua Zhou* \\ School of Transportation Engineering \\ Tongji University \\ Shanghai, China \\ zhoushh@tongji.edu.cn
}

\author{
Xinwen Yang \\ School of Transportation Engineering \\ Tongji University \\ Shanghai, China \\ yangxinwen0603@163.com
}

\begin{abstract}
The cultivation of middle school students' scientific quality concerns the nation's future innovation capacity and comprehensive national strength. The practical experience of developed country shows that scientific quality education starting from primary and secondary education stages is crucial for innovative talents to carry out scientific research in the future. To begin with, this paper analyzes the current situation and characteristics of middle school science education in our country, then analyzes the current situation and characteristics of middle school science education abroad. Finally, this paper explores a university laboratory service mode facing "middle school scientific quality education". This mode can overcome the shortage of exam-oriented education, motivate middle school students' scientific innovative thinking, and provide useful reference for the cultivating mode of middle school students' scientific quality in our country.
\end{abstract}

Keywords-quality education; scientific quality; middle school student; university laboratory

\section{SCIENTIFIC QUALITY AND SCIENTIFIC QUALITY EDUCATION}

Scientific quality mainly consists of five elements such as scientific knowledge, scientific abilities, scientific methods, scientific consciousness and scientific characters. In those five elements, scientific knowledge is the foundation of scientific quality. It's a valuable legacy accumulated and passed on by generations of humanity, and the cornerstone for middle school student to work on related scientific research in the future.

Scientific methods are the formulas people act accordingly when conducting scientific researches. A typical example is data collection, data analysis, hypothesis proposal, experimental validation, and conclusion.

Scientific abilities cover a wide range; mainly include experimental ability, critical thinking ability, comprehension ability and innovation ability. It's the most important link in scientific quality education, and the core of scientific quality. Possessing scientific abilities means possessing the sustainable development capacity for initiatively exploring and mastering new knowledge.

Scientific characters and consciousness are related to students' nonintellectual factors. Firm wills, down to earth style and modest and prudent attitude are all embodiments of scientific characters. Scientific consciousness means that even if students are not very clear about the theoretical reasons behind some scientific phenomenon they encounter in life, they can still connect it with a corresponding scientific discipline.

The scientific quality education aiming at middle school students is a process. The foundation of this process is students' scientific knowledge accumulation. The process is to cultivate and develop students' scientific abilities, and let them master certain scientific methods, and then motivate them to form scientific consciousness based on that foundation.

Scientific quality and scientific quality education has always been a hot issue for the education circle at home and abroad.

The overseas study of this issue started early, many exploration and attempt has been made. Early as 1916, the pragmatism educator John Dewey published Democracy and Education, on account of the American child education that only focused on knowledge indoctrinating and divorced from practice at that time. In this book, he suggested the "focusing on children, learning by doing" educational thought. He believed that the teaching should follow five steps, which are raising question, clarifying the question, proposing hypothesis, clarifying the hypothesis and validating by experiment. This procedure of five steps is called "the five-step thinking method". The pragmatism education movement initiated by Dewey didn't consider science education as pure knowledge 
indoctrinating any more, but as a scientific process and procedure [1].

According to the textual research of experts in western developed countries, the expression "scientific quality" appeared in the General Education in Science written by J. Conant, who was the Harvard president at that time. It was published in 1952. In that book, J. Conant included scientific quality as a part of the general education, but he didn't further explain and define this concept. The concept hadn't been defined until 1958, educator Ph.D. Hurd gave scientific quality a complete description in his magnum opus, Science Literacy: Its Meaning for all American Schools, in which he raised many original ideas, and included scientific quality into the range of basic education [2].

The concept and theory of scientific quality proposed by Ph.D. Hurd didn't draw much attention of the society since the focus point of science education was disciplinary structure back then. The concept of scientific quality hasn't been widely accepted by society until late 1960s, many theories and researches were born out of it since then. At this stage in western developed countries, it is generally believed that the content of scientific quality consists of two parts, one is scientific terms and concepts, and the other is the skills one must be equipped with for scientific experiment.

By the time of late 1970s, scientific quality education had become the center of the science education evolution in western developed countries. America was at the forefront in the field of scientific quality education development at that time. One of the most representative results was the "threedimensional theory" proposed by Professor Miller, the director of Chicago International development center, in 1983. This theory suggested that scientific quality consists of three aspects, the first was to master scientific terms and concepts, the second was to understand the scientific processes and methods used for solving problems in reality, the third was to understand the relationship between science, technology and society(STS). In the 90s some other developed countries added the forth aspect, which was the basic understanding of scientific emotional attitude and value.

After that, American Association for the Advancement of Science developed the Science for all Americans: Project 2061 report. This report gave a much broader definition for scientific and cultural quality. Scientific and cultural quality includes many aspects of mathematics, technology, natural science and social science, such as familiarity with nature and respect for the unity of nature, understanding of the codependent methods of mathematics, science and technology, comprehension of the theories behind some important scientific concepts, possession of scientific thinking ability, awareness of the advantage and limitation of mathematics, science and technology as a common cause for humanity, the ability to use scientific knowledge and thinking process to solve social and personal problems. This idea has brought huge influence to science education since the $90 \mathrm{~s}$ all around the world, including in China [3].

The scientific quality education in our country started relatively late. At the same time of the pragmatism education movement in America, the New Culture Movement, which started from 1915, brought the concepts of science and democracy to Chinese people, opened their eyes, and started a new era in Chinese scientific history. After the ups and downs in half of a century, the science and technology had had quite a development in our country, but still were far behind of the western developed countries. In 1978, the reform and opening policy brought life to the development of science in our country. Then in the $90 \mathrm{~s}$, the deepened reform of education in our country encountered the problem of the specific teaching mode can't meet the requirement for the students' all-round development. Therefore, the theory and practice of quality education was suggested [4]. Scientific quality is one of the topics. To reinforce the improvement of national scientific quality brought by basic education, the present Basic Education Curriculum Reform for compulsory education explicitly states that the new curriculum should be able to equip students with primary innovative spirits, practical ability, scientific literacy and humanistic quality [5]. Thus, the cultivation of scientific literacy has been included in the basic curriculum. The Outline of the Action Plan for the Nation's Science Literacy enacted by China Association for Science and Technology also states that equipping all the citizens of the People's Republic of China who are over 18 years old with certain science literacy should be an goal achieved in the near future through education [6].

\section{The Characteristics of Middle School ScIEnCE EDUCATION AT HOME AND ABROAD}

\section{A. The Middle School Scientific Learning Status in Our Country}

On the contrary of the quality education praised highly in our country's education circle, the primary school and middle school education are still mainly exam-oriented at present in China, due to the existence of the entrance examinations for high schools and universities, which are the guidance of educators' and students' action.

The exam-oriented education has been heavily criticized since the day it was born. As an education mode serving for selective test, its main problems are as follows:

\section{1) Unilateral teaching contents}

Due to the pressure from the entrance examinations for high schools and universities, teachers are emphasizing the contents of the examination in the limited time, even constantly repeat them to strengthen students' memories. On contrary, the contents that are not related to the exam are mentioned briefly or even omitted. This way of teaching will cause a knowledge limitation in the students' future study.

\section{2) Confined learning environment}

The school life of middle school students are confined between school and family. They seldom take part in the practice and learning outside of class, the priority in school is classroom learning. This learning mode would easily form a confined environment, in which students only concern about what happens in the class and don't pay attention to the outside world. Students become narrow-minded this way. 


\section{3) Single teaching mode}

The middle school education is mainly spoon-feeding style; teachers cram students with all kinds of knowledge, and students consolidate the knowledge by all kinds of exercises. Students are often misled to learning by memorizing not understanding, their exploration abilities are deprived. Given enough time, their abilities to explore and innovate in an unknow world will be deprived, too.

Therefore, when apply the exam-oriented education mode to scientific quality education; the result is not hard to guess. Exam-oriented education maybe can force middle school students to learn scientific knowledge and form scientific awareness, but it can't cultivate scientific methods, scientific characters and scientific abilities.

The Scientific knowledge in middle school stage mainly consists of knowledge from physics, chemistry and biology three disciplines. As we all know, those three disciplines are all strongly related with experiments. Let students engage in hands-on experiments, explore questions in experiments, make sense of science knowledge, and innovate through divergent thinking. Students can exercise their experimental abilities, critical thinking abilities and innovation abilities. They can get to know the general scientific methods, and cultivate their scientific characters in practice. Scientific experiments are the best way for middle school scientific quality education. The pity is that scientific experiments have been twisted into "exam-oriented experiments", due to the infiltration of the exam-oriented education. Many course experiments are simplified as demonstrations performed by teachers. The experiment sections are even omitted in some schools. The attentive problems, the experimental phenomena and the patterns often become abstract knowledge for students to remember. The consequence is the drop of middle school students' scientific quality.

\section{B. The Middle School Science Education Status Abroad}

The science education for middle school students is a highly-emphasized issue all around the world. This concern displays the following features.

\section{1) Emphasizing science education}

Countries like Britain and America usually list science as a core curriculum along with mathematics and English. From 1993 to 2013, five laws and regulations related with science curriculum were enacted in America. In Britain, the standards for science education are revised every 3 to 5 years [7]. The priority of the science curriculum ensures the effective implement of the science education. Many scientific activities are held in British middle schools, these activities can stimulate students' interests in science though hands-on practice, as illustrated in Fig.1.

\section{2) Optimizing faculty quality}

Science teachers are the most direct executor of middle school students' science education. The "Science Education Act" plan enacted by Australian government provides professional training, favorable working condition, competitive salary and specific organization and environment to attract and cultivate science teachers who are equipped with science quality and sustainable development capacity [8]. American Government also enacted the "teaching for innovation" plan, providing professional training for thousands of new science teachers [9].

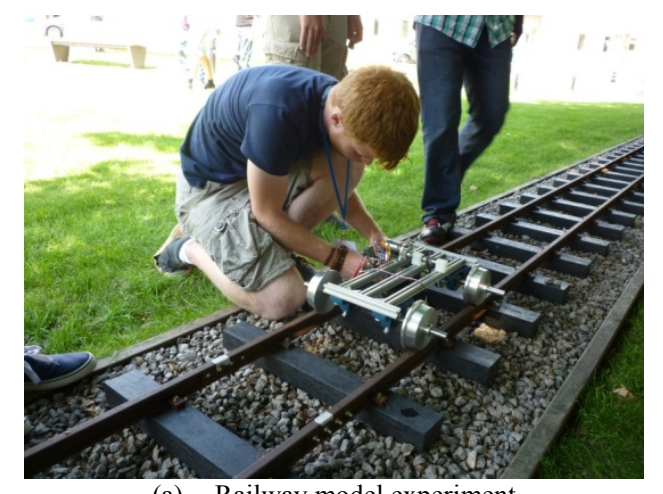

(a) Railway model experiment

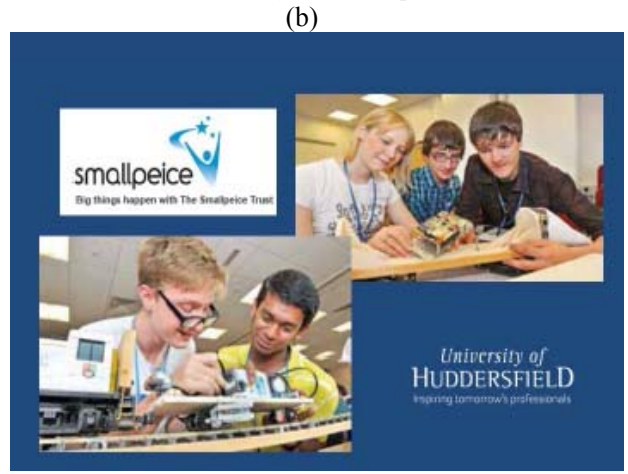

(b) The combination of university and middle school experiments in Britain

Fig.1 Many scientific activities are held in British middle schools

\section{3) Focusing on active explorations}

The science education generally follows the principle of "focusing on explorations" all around the word, which means to attach great importance to the stimulation of students' learning interests and exploring initiative. Britain, France, Mexico and Spain all enacted science education outlines and curriculums that "focus on explorations" [10].

\section{4) Fully utilizing resources}

America has more enriched experiences in integrating social resources to promote science education. The government relies on the civilian alliances of talents in scientific fields and private enterprise to provide a large amount of fund for science education. Also, the government coordinates different social departments to act together and provide a proper environment for science education. Museums and other scientific venues often hold experience events for teenagers.

\section{The AdVAntage of UnIVERsity LABORATORY SERVING FOR MIDDLE SCHOOL STUDENTS}

The ultimate goal for the compulsory education, high school education, even university education in our country is to cultivate innovative talents. Putting the word "innovation" in the middle school scientific education is to require middle school students to have the ability of exploring knowledge by 


\section{B ATLANTIS PRESS}

themselves, mastering the knowledge, and discovering new knowledge on that basis, then repeating that process. By this way, students will possess the sustainable development capacity for scientific research.

Due to the exam-oriented high school education and students' scarce experimental opportunity, a problem we often have to face is the disconnection between university science education and high school science education. Study in college emphasizes independent exploration and innovation. Many high school students feel lost when they start their college life, because the age-old exam-oriented education has given them a wrong idea that they only need to follow the rules in high school, exploration and innovation is for university. Yet in fact, creativity is needed throughout our life, the cultivation of creativity shouldn't be put aside due to a certain education mode.

After reviewing the characteristics of foreign scientific education, the idea of using university laboratory to serve middle school students emerge naturally. The reason is that university laboratories have more complete equipment and can perform experiments of various disciplines. At the same time, there are specialized teachers to guide the students. Using university laboratories for middle school students' scientific exploration can fill in the blank of high school students' handson experiments. It can broaden the horizons of students, cultivate independent innovative thinking, and connect the broken link of creativity cultivation between university and middle school. From the universities' point of view, it's helpful for breaking the education barrier and improving the usage rate of resources.

\section{MEASURES OF COMBINING UNIVERSITY LABORATORY AND HigH SCHOOL SCIENTIFIC QUALITY EDUCATION}

\section{A. Organizing Summer camps and laboratory visits}

There are many existing cases. Take Tongji University as an example, every summer junior and senior high school students come to visit and study at the Automobile and traffic laboratories in Jiading campus.

\section{B. Open university laboratories for society-Scientific innovation activities led by university teachers}

Many domestic universities has held activities of this nature, such as the "Prospective Ph.D. cultivating station" has been set up in Jinling high school by Nanjing university. More than 20 professors and 42 students pair up to do scientific researches [11]. The "Middle school student talent plan" has been pushed out by Zhejiang University and 4 high schools, which allows high school students to enter college laboratory and allows tutors to cultivate students individually according to their interests [12].

\section{Cooperation between College students and middle school in experiments}

In their spear time, college students can lead high school students to do experiments and researches, or include them into their own experiment research and exchange thoughts. For example, include middle school students into the 2016
"Zhixing Cup" Shanghai university student social practice contest and "Fellow Traveler" transportation science and technology competition.

\section{Bringing modified university laboratory equipment into middle school classroom}

Different from aforementioned project type measures, putting the experimental device in middle school can foster a sound environment for scientific experiments. For example, the simulation technology for high speed railway operation organization, which will be presented in the form of equipment and experiment in middle school innovation classroom, can act as a pictorial experimental teaching tool that inspires students' innovative thinking.

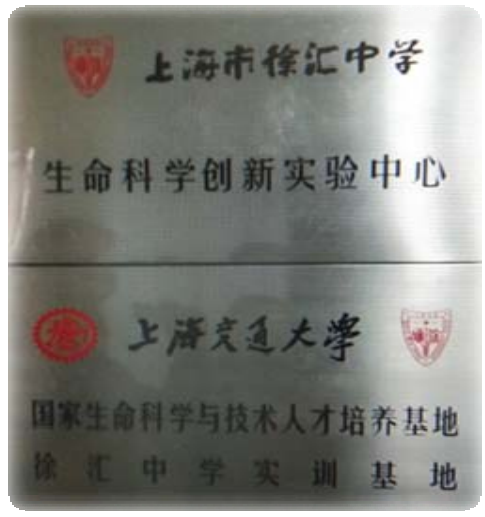

(a)

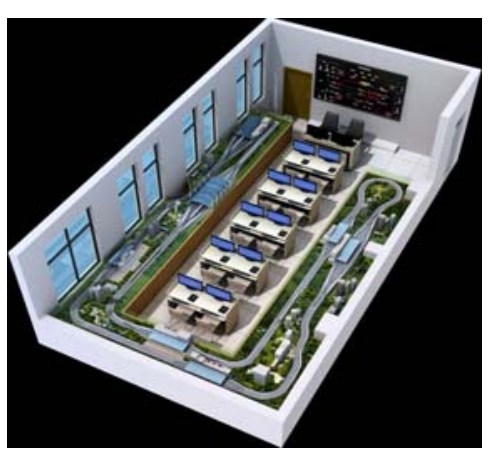

(b)

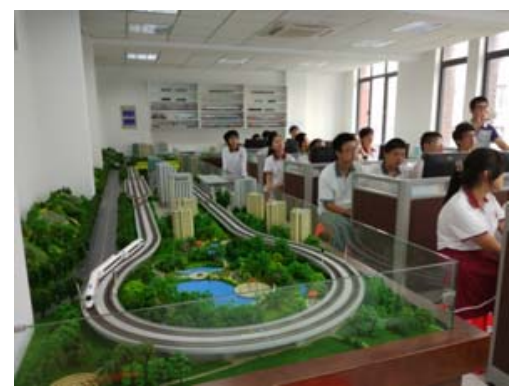

Fig.2. Examples of combination between Shanghai university laboratory and middle school Innovation experiment. 


\section{CONCLUSION}

At present, middle school students' scientific quality education generally is not optimal in China. Open the advanced resources of university laboratories to the middle school students will improve the status quo of middle school students' scientific quality education. The Rail Transit System Simulation Laboratory in Tongji University makes full use of the characteristics of university laboratory, and establishes related experimental base together with many middle schools in Shanghai. It plays a crucial part in the cultivation of middle school students scientific interests, and this education method is worth promoting.

\section{ACKNOWLEDGMENT}

This research was financially supported by the Project for Teaching Reform and Construction of Tongji University in 2015-2016.

\section{REFERENCES}

[1] F.K. Dong, "The design and Analysis of biological science inquisition activity at home and abroad," Wuhan: Central China Normal University, 2005. (In Chinese)

[2] X.L.Pan, "Practical research into physics teaching strategies for cultivating scientific literacy of senior high school students," Hunan: Hunan Normal University, 2011. (In Chinese)

[3] S.Y.Wang, "Evolution of educational idea for scientific quality abroad," Science \& Technology Vision, No.33, 2011, pp.35-40. (In Chinese)
[4] Task Team, "The concept, innotation and related theory of qualityoriented education," Educational Research, No.2, 2006, pp..3-10. (In Chinese)

[5] State Commission for Restructuring the Economic System, Renmin University of China, China Development Institute (Shenzhen, China) Joint Research Team, "Development Report of China's international competitiveness," Beijing: China Renmin University Press, 1997. (In Chinese)

[6] The Public Scientific Literacy in China Investigation Research Team of China Association for Science and Technology, "The 2001 public scientific literacy in China investigation report," Beijing: Popular Science Press, 2002. (In Chinese)

[7] H.Y.Sun, Y.W.Xiao, "How should we teach science today?" Primary \& Secondary School Management, No.12, 2014, pp.49-51. (In Chinese)

[8] Y.G.Li, "The science education action plan for primary and secondary schools in Australia," Educator, No.1, 2011, pp.45-47. (In Chinese)

[9] G.F.Yang, "Obama's reform on math and science education," Primary \& Secondary Schooling Abroad, No.11, 2013, pp.10-15. (In Chinese)

[10] P.J.Li, "Analyzing the international features between social science popularization facility and school science education from the perspective of the development tendency of foreign science education facing the juvenile," On the theoretical and practical studies of science popularization-proceedings of the international forum on PCST studies and the 17th national conference on the theoretical study of science popularization, 2010. (In Chinese)

[11] Z.M.Zhang, Y.M.Zhou, X.W.Tang, "Scientific edification and individualized education-the "middle school student talent plan" of Zhejiang University," China Science \& Technology Education, No.11, 2015, pp.21-23. (In Chinese)

[12] X.L.Yu, H.X.Zhang, X.Gong, Y.Sun, W.Li, "Exploration and Reflection on Joint Program between High School and University in Cultivating Creative Talents-Taking the "Potential Doctor Workshop"of J High School and University as an Case," Journal of Educational Science of Hunan Normal University, Vol.15, No.2, 2016, pp.64-70. (In Chinese) 